\title{
Uma Minissérie em Três Capítulos: Sequestro, prisão e julgamento de Adolf Eichmann
}

\author{
Desirée Mattos Soares ${ }^{1}$
}

\begin{abstract}
Resumo
Adolf Eichmann, ex-oficial da SS de Hitler, sequestrado em maio de 1960 no subúrbio de Buenos Aires, teve partes de sua trajetória (sequestro, prisão e julgamento) noticiadas diariamente pelos jornais argentinos La Prensa e La Razon. De acordo com o sociólogo francês Edgar Morin, o século XX inaugura uma imprensa periódica exclusivamente romanesca - sentimental, aventurosa e policial. A dramatização tende a preponderar sobre a informação propriamente dita. A luz da obra de Morin e demais contribuições, o presente artigo analisa o conteúdo dos jornais e demonstra como Eichmann tornou-se um personagem novelesco, que adquiriu fama e sobreviveu graças à exposição midiática sensacionalista e cinematográfica dada a seu caso.
\end{abstract}

Palavras-chave: Análise de Conteúdo, Adolf Eichmann, Edgar Morin, Cultura de Massas.

\begin{abstract}
Adolf Eichmann, a former SS officer of Hitler, abducted in May 1960 in the suburbs of Buenos Aires, had parts of his trajectory (abduction, arrest and trial) reported daily by the Argentine newspapers La Prensa and La Razon. According to the French sociologist Edgar Morin, the twentieth century inaugurates a periodic press exclusively romanesque - sentimental, adventurous and police. The dramatization tends to prevail over the information itself. In the light of Morin's work and other contributions, this article analyzes the content of the newspapers and demonstrates how Eichmann became a fictional character, who gained fame and survived thanks to the sensational and cinematographic media exposure given to his case.
\end{abstract}

Keywords: Content Analysis, Adolf Eichmann, Edgar Morin, Mass Culture.

Introdução

\begin{abstract}
A justiça insiste na importância de Adolf Eichmann, (...) aquele homem dentro da cabine de vidro construída para sua proteção: altura mediana, magro, meia-idade, quase calvo, dentes tortos e olhos míopes, que ao longo de todo o julgamento fica esticando o pescoço para olhar o banco de testemunhas (...), que tenta desesperadamente, e quase sempre
\end{abstract}

\footnotetext{
${ }^{1}$ Graduanda em Relações Internacionais pela Universidade Federal Rural do Rio de Janeiro - UFRRJ. Email: desireemattossoares@gmail.com.
} 
consegue, manter o autocontrole, apesar do tique nervoso que the retorce a boca (...). (ARENDT, 2013, p. 15).

Sequestrado num bairro operário do subúrbio de Buenos Aires em maio de 1960, Ricardo Klement, o homem que os agentes do comando israelense acreditavam ser Adolf Eichmann, foi levado preso para Israel após confirmar sua verdadeira identidade e redigir uma declaração na qual "concordava" em ser julgado por um tribunal israelense (SOARES, 2017, p. 11).

O julgamento do ex-Tenente-coronel da SS, dirigente da emigração forçada (expulsão) e do transporte de judeus para os campos de concentração e extermínio durante o regime de Hitler, foi o segundo maior processo de nazistas, depois dos Tribunais de Nuremberg ${ }^{2}$. O nazista foi objeto de cinco acusações pela Corte Distrital de Jerusalém, dentre as quais: crimes contra o povo judeu, crimes contra a humanidade e crimes de guerra (SOARES; XAVIER; WEY, 2017, p. 14). Decorridas 244 seções, Eichmann foi condenado à pena de morte por enforcamento e executado na madrugada do dia 31 de maio de 1962 (ARENDT, 2013, p. 266 e 271).

Embora a posição de importância de Eichmann estivesse em estrato mais baixo na hierarquia nazista ${ }^{3}$ (não fosse o fato de ter atuado no escritório de assuntos judeus repartição que esteve à frente da execução dos planos de extermínio de Hitler - é pouco provável que conhecêssemos sua história), periódicos argentinos, ao reportarem notícias de seu sequestro e prisão em Israel, referiram-se ao nazista como: “indivíduo que proyectó la liquidación de la raza hebraica"4; "el exterminador de judios"5; "el mayor enemigo viviente del pueblo judío"6.

Foram esses os jornais La Prensa e La Razon, periódicos tradicionais da província de Buenos Aires, nos quais, durante fins de maio e princípios de junho de 1960, o leitor argentino poderia encontrar, quase que diariamente, notícias ricas em detalhes e carentes

2 MUCZNIK, Esther. Ich Bin Adolf Eichmann. Disponível em: <http://www.yadvashem.org/yv/es/education/articles/article_mucznik4.asp>. Acesso em: 11 jun. 2017.

${ }^{3}$ Eichmann teve por superior a Ernst Kaltenbrunner, que respondia a Henrich Müller, que por sua vez, estava subordinado a Reinhard Heydrich, que obedecia as ordens de Heinrich Himmler. Para maiores detalhes, vide organograma da hierarquia nazista no "Anexo I" ao final deste trabalho, fotografado da sessão sobre Eichmann no Museu do Holocausto de Buenos Aires, Argentina.

${ }^{4}$ Disponível no Jornal La Prensa, "Prepárase el juicio contra el nazi Eichmann en Israel”, 27/05/1960.

5 Disponível no Jornal La Razon, "Otro misterio en el caso Eichmann: desaparecen la mujer y los hijos", 04/06/1960

${ }^{6}$ Disponível no Jornal La Razon, "Revelóse en Viena que el criminal de guerra nazi Eichmann fue sacado de la Argentina en un submarino por agentes de los servicios secretos de Israel", 26/05/1960. 
em "novidade" " sobre o caso Eichmann. Como um mero expectador da trama envolvendo Eichmann; sua esposa e filhos; vizinhos e autoridades do governo argentino e israelense, o leitor interessado, num ato praticamente religioso, ao sentar na poltrona da sala de estar para folhear o jornal, se depararia com mais um capítulo novelesco, que poderia despertarlhe as sensações de curiosidade, raiva, dúvida, surpresa, desgosto, dentre outras.

Nesse sentido, a obra do sociólogo francês, Edgar Morin (1997), pode oferecer as ferramentas teóricas necessárias para compreender esse fenômeno. Em Cultura de Massas no Século XX, Morin discute o papel da indústria cultural e verifica sua tendência para homogeneizar sob um denominador comum a diversidade dos conteúdos - prática denominada pelo autor como "sincretismo" - o que se reflete em certa medida, no setor da informação e no setor do romanesco:

\begin{abstract}
No setor da informação, é muito procurado o sensacionalismo (isto é, essa faixa de real onde o inesperado, o bizarro, o homicídio, o acidente, a aventura irrompe na vida quotidiana). Tudo o que na vida real se assemelha ao romanesco ou ao sonho é privilegiado. (...) Esse prodigioso e supremo sincretismo se inscreve na busca do máximo de consumo (MORIN, 1997, p. 36$37)$.
\end{abstract}

O presente artigo tem o objetivo de analisar o conteúdo dos jornais supracitados durante o período de 26 de maio a 15 de junho 1960, buscando demonstrar como Eichmann se tornou um personagem novelesco, à luz da obra de Morin (1997), dentre outras contribuições. Para esse fim, o trabalho está estruturado em três partes: na primeira, apresento de forma concisa as ideias do escritor francês somadas ao conceito de "Indústria Cultural" dos filósofos alemães Adorno e Horkheimer; na segunda parte, conheceremos a história dos periódicos argentinos La Prensa e La Razon e por fim, segue-se a análise do conteúdo desses jornais, destacando-se algumas manchetes veiculadas e elucidandose os critérios escolhidos para o estudo proposto.

\title{
Indústria cultural e cultura de massas
}

\footnotetext{
${ }^{7}$ Houve excesso de repetições de notícias com um ou outro detalhe acrescentado ao caso Eichmann, criando a ilusão de que o leitor estava diante de algo novo toda vez que lia sobre o caso.
} 
Maria Campos, em Mitos da mídia (2008), discute o processo de mitificação de personagens produzido pela mídia. Segundo a autora, os "mitos" da mídia têm em comum o fato de serem mercadorias culturais. Como parte da indústria do entretenimento, essas personagens adquirem fama e sobrevivem graças à exposição midiática. $\mathrm{O}$ trecho a seguir sintetiza sua tese:

Os meios de comunicação de massa têm provocado muitos fenômenos culturais no mundo contemporâneo. Um deles é o processo de mitificação de personagens produzidos por esses meios, ou seja, o surgimento de celebridades, heróis e estrelas. Tanto aqueles que possuem talento, desenvolvendo um trabalho consistente, quanto os que não têm qualquer dom extraordinário, podem tornar-se um personagem da mídia (CAMPOS, 2008, p. 2).

O conceito de "Indústria cultural" relaciona-se à forma de produzir cultura no período industrial capitalista. O termo cunhado década de 1940 pelos filósofos Max Horkheimer e Theodor Adorno, intelectuais da Escola de Frankfurt, qualifica particularmente a situação da arte na sociedade capitalista industrial, caracterizada por processos de produção que pendiam, sobretudo ao lucro.

Utilizando o conceito dos filósofos alemães, Campos (2008) chama a atenção para este fenômeno da "Indústria Cultural", que consiste na transformação da cultura em mercadoria, produzida para a obtenção de lucro. Tal indústria é caracterizada pela "tendência à padronização das mensagens; a busca por novidade; a produção de mercadorias que garantam lucratividade (...) e a ilusão de que o consumidor tem liberdade de escolha e de que está diante de algo novo" (CAMPOS, 2008, p. 2-3). A partir dessa indústria cultural, surge uma cultura de massa,

produzida segundo as normas maciças da fabricação industrial e propagada pelas técnicas de difusão maciça (mass media) destinando-se a uma massa social, isto é, um aglomerado gigantesco de indivíduos compreendidos aquém e além das estruturas internas da sociedade (classes, família, etc.). (MORIN, 1997, p. 14).

Nessa perspectiva, são meios de difusão da cultura de massas: os jornais, as estações de rádio e os canais de televisão - instituições burocraticamente organizadas, cujos produtos finais são mercadoria e a lei fundamental é a lei do mercado: 
A cultura de massa, no universo capitalista, não é imposta pelas instituições sociais, ela depende da indústria e do comércio, ela é proposta. (...) Passa sempre pela mediação do produto vendável e por isso mesmo toma emprestadas certas características do produto vendável, como a de se dobrar à lei do mercado, da oferta e da procura. Sua lei fundamental é a do mercado. (MORIN, 1997, p. 46).

Segundo Morin (1997), a organização burocrática filtra a ideia criadora, submetea a exame antes que ela chegue às mãos daquele que decide - o produtor, o redator-chefe. Tal decisão é tomada de acordo com critérios de noticiabilidade estabelecidos previamente pela redação (no caso de um jornal), que levam em consideração a rentabilidade eventual do assunto proposto (iniciativa privada) e sua oportunidade política (Estado) (MORIN, 1997, p. 24).

Em se tratando especificamente dos jornais, Morin (1997) afirma que é no começo do século XX que se forma uma imprensa periódica, exclusivamente romanesca (sentimental, aventurosa e policial). A dramatização tende a preponderar sobre a informação propriamente dita. Os temas fundamentais do cinema passam a ser privilegiados junto à informação:

No sensacionalismo, as balaustradas da vida normal são rompidas pelo acidente, a catástrofe, o crime, a paixão, o ciúme, o sadismo. (...) É esse universo de sonho vivido, de tragédia vivida e de fatalidade que valorizam os jornais do mundo ocidental (MORIN, 1997, p. 100).

A informação tende a estruturar o acontecimento de modo romanesco ou teatral. Um exemplo dessa tendência está expresso no jornal La Razon, quando este veiculou a notícia do desaparecimento da esposa e filhos de Eichmann. A própria manchete sugeria um ar cinematográfico: "Otro misterio en el caso Eichmann: desaparecen la mujer y los hijos”. Confira parte da notícia, cuja narração se assemelha a de um filme de suspense:

A localização, captura e transporte ao exterior do país onde o criminoso nazista Adolfo Eichmann, que LA RAZON apresentou em todos os detalhes ao mundo inteiro, entrou agora em uma nova fase, verdadeiramente cinematográfica: pouco antes das 07 de hoje, quando uma espessa névoa cobriu Buenos Aires, abandonou sua casa (...) Klaus Eichmann, filho mais velho [de Adolfo Eichmann] (...), sua 
esposa, Margarita (...) e a pequena filha dos dois. Eles foram acompanhados por três homens que portavam maletas com os elementos mais indispensáveis. Em uma caminhonete, foram depois a rumo desconhecido (La Razon, 04 jun. 1960, grifo nosso).

Conforme veremos no decorrer desta análise, o tom romanesco está presente em diversas notícias do caso Eichmann, transformando-o no que Morin (1997) traduz no conceito de "olimpiano". Embora o autor esteja se referindo às grandes "estrelas" da mídia, que são tratadas como divindades - ocupando o "Olimpo" da mitologia grega - e tem suas vidas privadas consideradas relevantes para serem noticiadas, neste trabalho, compreende-se que a notoriedade concedida ao caso Eichmann e a repercussão de seu sequestro conferem a ele um papel de personagem novelesco durante o período em que diariamente puderam ser encontrados nos jornais, capítulos de sua "minissérie". No tópico a seguir conheceremos a história dos jornais analisados neste artigo.

\section{História dos jornais La Prensa e La Razon}

\section{La Prensa}

La Prensa foi fundado pelo aristocrata José C. $\mathrm{Paz}^{8}$ em 18 de outubro de 1869. O periódico teve como primeiros diretor e editor, Cosme Mariño e Jorge Cook, respectivamente. A partir da primeira edição, o jornal começou a sair todos os dias às 15h. O gigantesco edifício construído pela família Paz na Avenida de Mayo, n 575, foi a primeira sede do jornal.

A escultura da deusa da sabedoria Athena, que representa a liberdade de expressão (com uma tocha em uma das mãos e um escrito na outra) constituiu-se no símbolo marcante do edifício La Prensa. Um segundo símbolo foi a sirene, que se tornou famosa por anunciar os eventos mais importantes. Anterior ao rádio, a sirene era um dos poucos meios de comunicação através do qual as notícias nacionais e internacionais mais importantes puderam ser transmitidas imediatamente na cidade de Buenos Aires ${ }^{9}$.

\footnotetext{
${ }^{8}$ José C. Paz foi um dos mais ricos membros do círculo político que governou a Argentina nos anos 18801916 - a chamada "Generación del Ochenta". Paz foi o primeiro deputado nacional do Partido Autônomo Nacional (PAN) e mais tarde foi embaixador do presidente argentino Julio Roca na Espanha e na França. ${ }^{9}$ La Prensa, "La inauguración de la farola del diario La Prensa",1898.
} 


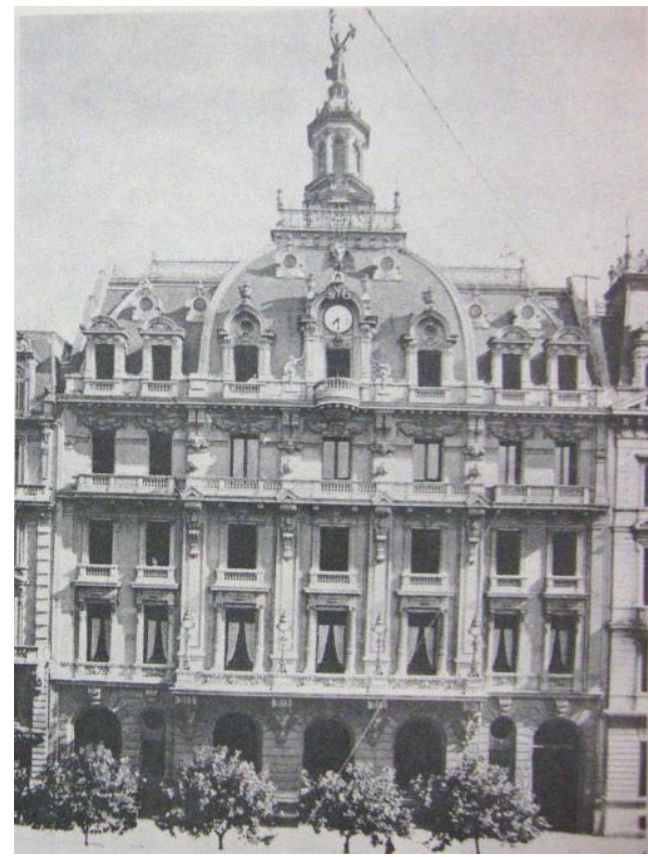

Figura 01: Edifício do periódico La Prensa, 1910.

Fonte: Revista Summa, no 215/216. Agosto de 1985. Buenos Aires, Argentina.

La Prensa, propriedade da família Gainza Paz, desde sua fundação foi vinculado ao Partido Autônomo Nacional (PAN) - partido de orientação liberal-conservadora que permaneceu no governo argentino por três décadas seguidas. Em 1898, José C. Paz transferiu a responsabilidade do jornal para seu filho Ezequiel Pedro Paz, que fez do $L a$ Prensa um dos jornais mais ilustres do país, com correspondentes em todo o território argentino, bem como outros países da América do Sul, Estados Unidos e Europa. Em 1943, Ezequiel Paz passou a direção para o sobrinho Alberto Gainza Paz, que foi sucedido pelo filho, Máximo Paz.

Como porta-voz do conservadorismo da "Geración del Ochenta"10, La Prensa questionou a expansão dos direitos que impulsionaram as novas correntes políticas e sociais na luta pela abertura democrática, o surgimento dos sindicatos e as exigências dos direitos trabalhistas. De acordo com o jornalista Rogelio Alaniz ${ }^{11}$, La Prensa, juntamente com outros veículos de orientação liberal-conservadora, forneceu apoio ao primeiro golpe de estado produzido na Argentina, que derrubou o presidente Juan Yrigoyen em 1930.

\footnotetext{
${ }^{10}$ Termo pelo qual ficou conhecida a elite governamental da República Argentina durante o período de 1880-1916.

11 ALANIZ, Rogelio. La clausura del diario La Prensa. El Litoral, 21 out. 2009. Disponível em: $<$ http://www.ellitoral.com/index.php/diarios/2009/10/21/opinion/OPIN-04.html>. Acesso em: 31 out. 2017.
} 
Durante o governo do presidente Juan Domingo Perón (1946-1955), La Prensa teria tomado uma posição abertamente anti-peronista. Nos anos seguintes, o periódico passou por problemas financeiros, tendo que pagar multas altíssimas por irregularidades administrativas e foi alvo de denúncia de violação de direitos trabalhistas. Em princípios de 1950, como consequência desses acontecimentos, o jornal foi expropriado.

Em 1956, após o golpe militar que destituiu Perón, o jornal retornou à família Gainza Paz. La Prensa apoiou os governos dos subsequentes regimes ditatoriais e demonstrou oposição aos governos do período de redemocratização argentina. Na década de 1990 o jornal decretou falência e foi adquirido pela companhia Multimedios La Capital - do empresário Florencio Aldrey Iglesias - que dirige o jornal atualmente. A propriedade do edifício La Prensa foi transferida para o governo da cidade de Buenos Aires, que o transformou em um centro cultural.

\section{La Razon}

Foi o jornalista Emilio B. Morales, que em $1^{\circ}$ de março de 1905, fundou o periódico La Razon, com sede na rua Flórida n 69/71, na cidade de Buenos Aires, Argentina. A primeira edição do jornal contava com matérias sobre a guerra russojaponesa, a bolsa de valores, um naufrágio do vapor Chile, as inundações no Chaco, dentre outros. La Razon tinha como prioridade fornecer notícias breves e de informação geral em lugar de matérias sobre os rumos da política.

Alguns anos mais tarde, o empresário e jornalista José Cortejarena propôs a Morales uma sociedade e a ampliação do jornal. Em 1911, o periódico permaneceu com Cortejarena, que mudou a sede para o edifício da Avenida de Mayo, $\mathrm{n}^{\circ} 760$, lançando várias edições diárias. Cortejarena faleceu em 1921. Foi sua viúva, Helvecia Antonini, que esteve à frente da sociedade até 1950.

Durante esse período, a direção do jornal era do advogado e professor, Angel Sojo, que já havia trabalhado como jornalista em $O$ Diário de Manuel Láinez. De acordo com a edição especial dos cem anos do jornal ${ }^{12}$, Sojo foi um dos grandes inovadores do periódico: criou a edição de domingo; incorporou um novo material gráfico; aperfeiçoou

\footnotetext{
${ }^{12}$ La Razon, "Los hitos de um vespertino que acompaña el pulso del país”, 15 abr. 2005. Disponível em: < http://edant.larazon.com.ar/diario_lr/especial/2005/04/15/0-957995.htm>. Acesso em: 30 out. 2017.
} 
palavras cruzadas, quadrinhos (alguns personagens tornaram-se clássicos, como "Ramona" e "Don Fulgencio", de Lino Palacio) e tiras de Dante Quinterno.

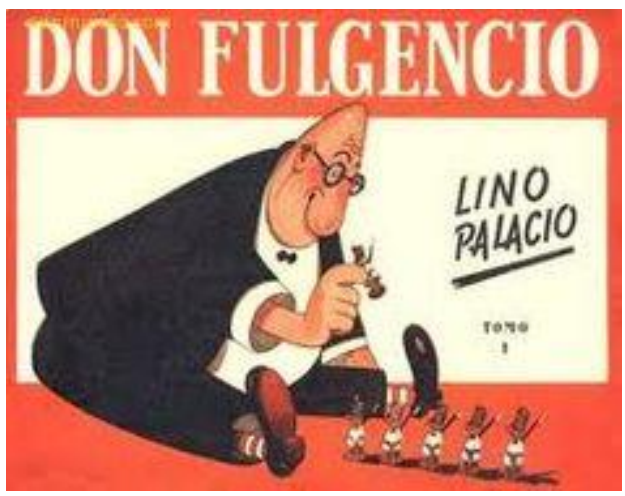

Imagem 2: Don Fulgencio, personagem das tiras cômicas de Lino Palacio.

Fonte: Pinterest

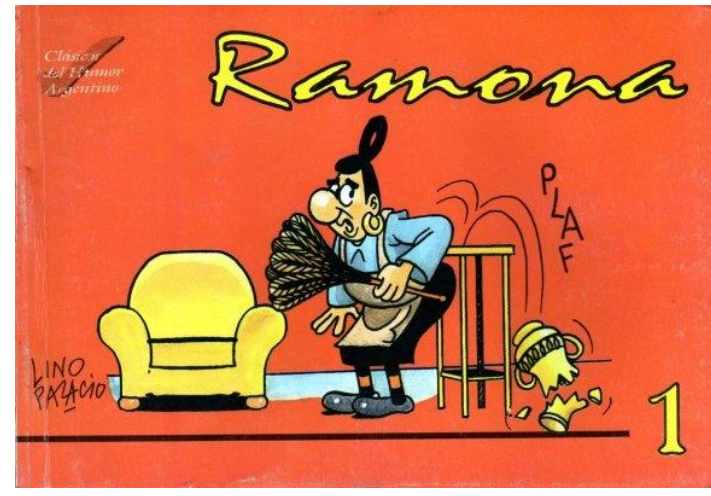

Imagem 3: Ramona, personagem das tiras cômicas de Lino Palacio.

Fonte: Pinterest

Como resultado de tais inovações, em 1925, o jornal contava com uma equipe de 800 funcionários, incluindo jornalistas e administradores e em 1928, já havia atingido a circulação de 220.000 cópias, número expressivo para a época. Por razões de saúde, Sojo teve de deixar o jornal em 1935, mas antes transferiu a sede para o edifício da Avenida de Mayo, $n^{\circ} 739$ e realizou outras mudanças importantes, como a incorporação de notas e relatórios de cores.

Quem assumiu a direção do jornal foi Félix Hipólito Laiño, que permaneceu no cargo por mais de cinco décadas. Em 1939, foi lançado o logotipo histórico do La Razon: letras brancas em um fundo cinza:

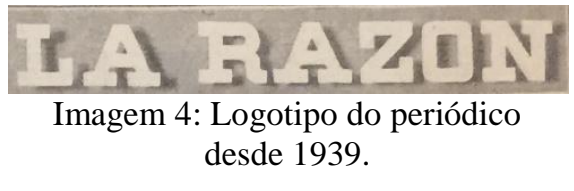

Fonte: La Razon, 26 mai. 1960

Durante a década de 1950 o jornal passou por um período de turbulência, sendo interposto pelo governo de Juan Perón. Mesmo depois do golpe de 1955, que depôs o presidente argentino, levou algum tempo para que seus proprietários (naquela época, a família Peralta Ramos) recuperassem a propriedade.

Novamente inserido no mercado, como um vespertino de ponta, La Razon passou por outras mudanças. Em 1964, inaugurou sua gráfica na rua General Hornos, nº 690. A administração e a redação do jornal também foram transferidas para esse edifício em 1977. 
Após alterações no cenário político argentino dos anos 1980 (com a queda do regime militar), muitos vespertinos caíram em declínio. Em 1984, Jacobo Timerman substituiu Laiño na direção do jornal. La Razon foi transformado em um "tablóide"13 matutino, promovendo um espaço de discussão política. Com a queda constante nas vendas, Timerman deixou a direção e o periódico sofreu sucessivos câmbios de propriedade e condução, que resultaram mais tarde em mudanças na orientação políticoideológica independente inicial do jornal.

Em 1992, o jornal foi adquirido pelo Grupo Spadone, que o tornou gratuito sete anos depois. Em 2000, o Grupo Clarín comprou 75\% das ações do periódico, que passou a ser um diário com um número bem menor de páginas, que publicava breves comentários das principais notícias do dia com forte opinião editorial, distribuído gratuitamente nos ônibus e metrôs de Buenos Aires.

La Prensa e La Razon, durante a década de 1960 (período analisado neste artigo), apresentavam divergências entre si relevantes, que os tornam importantes para este estudo. Em termos de orientação política, La Prensa identificava-se com o pensamento liberal-conservador, enquanto La Razon pode ser classificado como um jornal de orientação independente de grupos políticos. Quanto ao público leitor, não é o objeto de estudo deste trabalho apurá-lo, porém podemos compreender que La Prensa era apreciado pela aristocracia argentina ao passo que La Razon teria um alcance mais amplo (popular). A despeito de tais diferenças, conforme observaremos no tópico a seguir, as notícias sobre caso Eichmann veiculadas por ambos os jornais carregaram semelhantes aspectos que culminaram na transformação de Eichmann em um personagem de uma minissérie em três capítulos: sequestro, prisão e julgamento.

\section{Análise de conteúdo}

Para o presente estudo foram selecionados os seguintes critérios de análise: (1) importância dada ao caso Eichmann; (2) assinatura das notícias; (3) fontes consultadas; (4) personalidades políticas citadas e (5) posicionamento dos jornais a respeito de Eichmann. Cada apuração de dados teve como resultado um quadro informativo.

O primeiro critério escolhido foi a importância dada ao caso Eichmann. Para aferilo, foi verificado o espaço que as manchetes ocupavam nas páginas de ambos os jornais.

\footnotetext{
${ }^{13}$ Jornal que tem cerca de metade do tamanho padrão de um jornal habitual.
} 
A notícia mais próxima do caso foi encontrada na capa do jornal e a mais distante, na página 10. Vale ressaltar que algumas notícias de capa continuavam em outra página, podendo preencher de duas a quatro colunas. O quadro a seguir é o resultado desta análise.

\begin{tabular}{|l|l|l|}
\hline \multicolumn{1}{|c|}{ Lugar da notícia } & La Prensa & La Razon \\
\hline Capa & 3 & 2 \\
\hline Capa e continuação & 5 & 2 \\
\hline Páginas 2 a 5 & 6 & 0 \\
\hline Páginas 6 a 10 & 1 & 7 \\
\hline Total de notícias & 15 & 11 \\
\hline \multicolumn{2}{|c|}{ Quadro 1: Importância dada ao caso Eichmann } \\
\multicolumn{3}{|c|}{ Fonte: elaboração própria. }
\end{tabular}

Observa-se que a das 15 notícias veiculadas pelo La Prensa, mais da metade $(53,3 \%)$ ocupam a capa do jornal e outras seis $(40 \%)$ estão entre as primeiras páginas do periódico. Por sua vez, em La Razon, das 11 notícias, quatro ocupam a capa (36,3\%) e as sete restantes $(54,5 \%)$ estão entre as páginas seis e 10 do jornal. É importante lembrar que o espaço ocupado pela notícia em um jornal é definido por sua redação e envolve o trabalho de vários profissionais (dentre eles: o diagramador, o diretor de arte, o diretor de texto, o chefe de reportagem e o redator) e a escolha do que vai ser veiculado ou não, depende de alguns valores-notícia e do editorial do jornal.

O caso Eichmann preenchia os valores-notícia: (1) atualidade, por se tratar do recente anúncio do primeiro ministro israelense, Ben Gurion, de que Adolf Eichmann encontrava-se preso em Israel; (2) proeminência dos sujeitos envolvidos, considerada a personalidade de Eichmann no Terceiro Reich; (3) negatividade, uma vez que a figura do ex-oficial nazista relembra a experiência do Holocausto judeu; (4) continuidade, pois o desdobrar do caso renderia notícia para os próximos dias, o que de fato ocorreu e (5) relevância para o leitor, considerando-se, sobretudo, o fato de que a Argentina possui uma das mais numerosas comunidades judaicas do mundo: o país americano foi o segundo ${ }^{14}$ a receber o maior número de refugiados judeus durante a Segunda Guerra Mundial (SENKMAN, 2003, p. 37). Desse modo, o caso ganhou notoriedade em ambos os jornais, muitas vezes figurando entre a capa e as primeiras páginas dos periódicos.

O segundo critério analisado refere-se à assinatura das notícias. De acordo com o quadro a seguir, La Prensa teve aproximadamente $73 \%$ das notícias sobre o caso Eichmann sem assinatura do jornalista, ao passo que La Razon foi ainda mais longe, com

\footnotetext{
${ }^{14}$ Atrás apenas dos Estados Unidos e à frente do Brasil.
} 
$100 \%$ das notícias veiculadas sem assinatura. Tal fato gera a interpretação de que os jornais não tiveram interesse em responsabilizar nenhum de seus jornalistas pelos textos publicados. De acordo com Sousa, em Introdução à análise do discurso jornalístico impresso (2004), a abdicação da assinatura nos textos também pode ser uma forma de ocultar a origem de alguma informação, que pode ter sido externa, mesmo quando sujeita a reescrita. $\mathrm{O}$ jornalista profissional, ético e comprometido com seu trabalho assina seus textos por motivos óbvios, pois foi ele quem escreveu.

\begin{tabular}{|l|l|l|}
\hline \multicolumn{1}{|c|}{ Assinatura das notícias } & La Prensa & La Razon \\
\hline $\mathrm{N}^{\mathbf{o}}$ de notícias sem assinatura & 11 & 11 \\
\hline $\mathrm{N}^{\mathbf{o}}$ de notícias assinadas & 4 & 0 \\
\hline Total de notícias & 15 & 11 \\
\hline \multicolumn{2}{|c|}{ Quadro 2: Assinatura das notícias } \\
Fonte: elaboração própria.
\end{tabular}

No que concerne às fontes consultadas, estas podiam ser diários estrangeiros ou agências internacionais de notícia. Algumas matérias simplesmente não identificaram a origem da informação que estava sendo anunciada, como foi o caso da manchete do $L a$ Razon de 4 de junho, intitulada "Otro misterio en el caso Eichmann: desaparecen la mujer y los hijos", que noticiava o suposto "sumiço" de Vera Eichmann e de seus filhos do subúrbio de San Fernando; e também a manchete do La Prensa de 15 de junho, intitulada "Leyendas antissemitas en la calle Rivadavia", que noticiava que foram pichadas diversas inscrições de caráter antissemita e a favor do nazismo ao longo da avenida Rivadavia, em Buenos Aires. Ambas as manchetes, além de não indicarem fonte, também não foram assinadas pelos jornalistas.

\begin{tabular}{|l|l|l|}
\hline \multicolumn{1}{|c|}{ Fontes consultadas } & La Prensa & La Razon \\
\hline $\mathrm{N}^{\mathbf{o}}$ de diários estrangeiros & 10 & 7 \\
\hline $\mathrm{N}^{\mathbf{o}}$ de agências internacionais de notícia & 1 & 3 \\
\hline $\mathrm{N}^{\mathbf{o}}$ de notícias sem indicação de fonte & 1 & 3 \\
\hline Total de notícias & 15 & 11 \\
\hline
\end{tabular}

Quadro 3: Fontes consultadas

Fonte: elaboração própria.

A necessidade de publicar algo "novo" sobre o caso diariamente pode ser uma das principais respostas para a ausência de assinatura e de indicação de fonte em diversas matérias dos jornais. Manter o público interessado no próximo capítulo dessa minissérie significaria, juntamente com demais fatores, obter estabilidade nas vendas. Isso 
demandava conseguir informações das principais agências internacionais de notícias do período (AFP, United Press e ANSA) e verificar o que diziam os jornais estrangeiros ${ }^{15}$ sobre o desenrolar dos fatos.

Porém, se dentro de um curto espaço de tempo (24h), nada relevante ocorresse, então se repetiria em outras palavras o que já havia sido noticiado, como ocorreu com a informação de que a polícia local investigava detalhes da cédula de identidade de Ricardo Klement para comprovar se este era de fato Adolf Eichmann. Somente no jornal La Prensa, essa informação apareceu repetidamente nas notícias dos dias 1, 2, 4, 7 e 9 de junho, sem qualquer "novidade" significativa sobre os rumos da investigação, o mesmo ocorreu no La Razon nos dias 2 e 4 do mesmo mês.

De igual modo foi com a informação de que um possível encontro de Arturo Frondizi (presidente argentino) com Ben Gurion (primeiro ministro israelense), na França, poderia ser mediado por Charles de Gaulle (presidente francês), para que fosse resolvido o conflito gerado em torno da violação de soberania do Estado argentino comprovado o sequestro de Eichmann por agentes israelenses, notícia que foi publicada repetidas vezes em ambos os jornais. $\mathrm{O}$ tal encontro não passou de um simples rumor.

Quando a informação não era repetida, bastava que houvesse a mínima relação com o caso Eichmann para que virasse notícia, como na manchete do La Razon de 8 de junho, intitulada “Un precedente del caso Eichmann”. A notícia trazia uma riqueza de detalhes ${ }^{16}$ de um caso ocorrido em 1888 quando outro sequestro se deu em território argentino, do empresário inglês Jabez Balfour. Veicular um episódio de 72 anos antes, cuja similaridade ao caso atual só tinha o sequestro, reforça ainda mais a escolha da redação do jornal por publicar qualquer informação que levasse o nome "Eichmann" no título da notícia. Diante do exposto, verificamos que a redação de ambos os jornais não estava interessada em se comprometer com o conteúdo da notícia, mas apenas em vendêla.

\footnotetext{
15 Foram consultados os jornais: Frankfurter Allgemeine Zeitung, Neues Beutschland e Morgenpost (Alemanha); Kroner Zeitung e Neues Oesterreich (Áustria); Daily Telegraph, Daily Express e The Observer (Inglaterra); The New York Times, Daily News e Sunday Review (EUA); Le Monde (França); Haaretz e La información de Israel (Israel) durante o período analisado neste artigo.

${ }^{16}$ A notícia ocupava quatro colunas e era a única da página, sendo restante preenchido por publicidade, como pode ser observado na imagem 5 .
} 


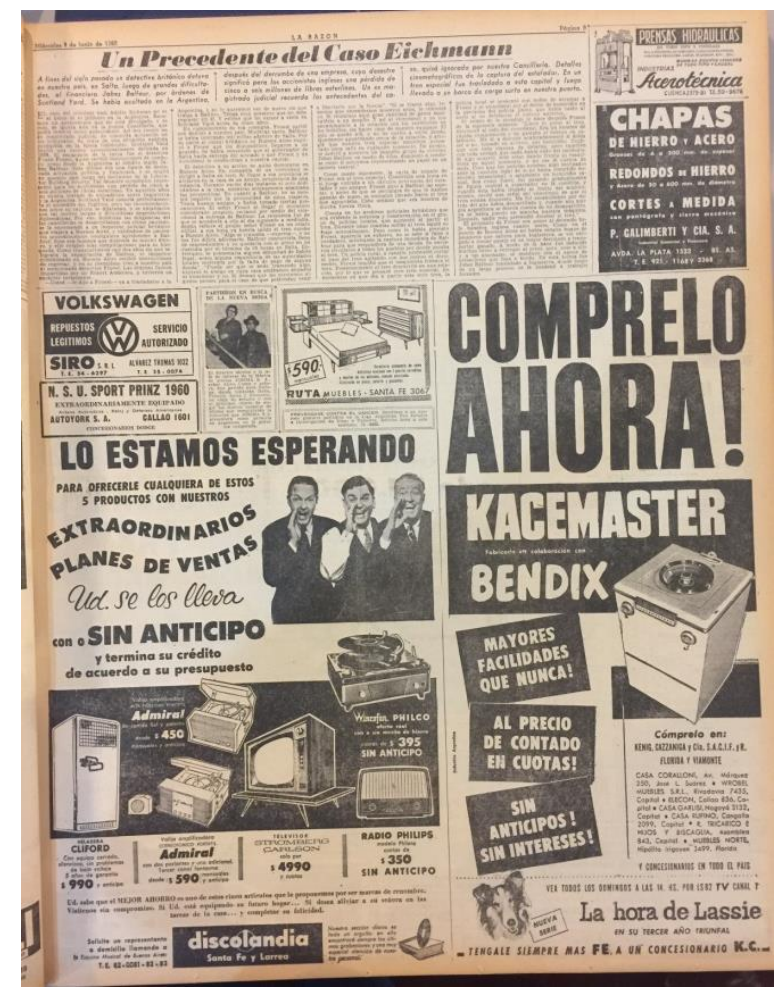

Imagem 5: "Um precedente do caso Eichmann". Fonte: La Razon, 08 jun. 1960

Uma minissérie não é feita apenas de um personagem. O recurso de citar figuras políticas foi amplamente explorado para conferir grandeza e relevância ao caso Eichmann. No desdobrar dos fatos, algumas personalidades políticas proeminentes tiveram suas falas (discursos e notas oficias) mencionadas ou mesmo publicadas integralmente, como em 7 de junho, quando La Prensa publicou a nota oficial do Ministério das Relações Exteriores israelense que pretendia esclarecer os rumores sobre o sequestro de Eichmann e no "capítulo" seguinte, em 9 de junho, quando foi divulgada a nota do governo argentino em resposta à recebida por Israel, solicitando a devolução de Eichmann ao território argentino.

No quadro a seguir, podemos conferir quem foram esses atores "coadjuvantes", quais papéis desempenharam na trama e quantas vezes seus nomes foram citados pelas notícias dos jornais. Note que somente o Primeiro Ministro israelense é citado em seis das 15 notícias do La Prensa. Em segundo lugar vem Golda Meir, Ministra das Relações Exteriores israelense, mencionada em quatro notícias por ambos os jornais. As autoridades israelenses desempenham um papel importante no cenário político envolto no caso do nazista. $\mathrm{O}$ anúncio de Ben Gurion de que Eichmann encontrava-se preso em Israel, seus discursos fervorosos em favor do julgamento do nazista por um tribunal 
israelense, para que a juventude judia conhecesse a história do Holocausto, encontrariam um público leitor judeu significativo, numa nação que recebera o segundo maior contingente de judeus entre 1939-1945.

\begin{tabular}{|l|l|l|l|}
\hline \multicolumn{1}{|c|}{$\begin{array}{c}\text { Personalidades políticas } \\
\text { citadas }\left(\mathrm{n}^{\mathbf{0}} \text { de vezes) }\right.\end{array}$} & \multicolumn{1}{|c|}{ Cargo político } & La Prensa & \multicolumn{1}{c|}{ La Razon } \\
\hline Ben Gurion & Primeiro Ministro israelense & 6 & 2 \\
\hline Arturo Frondizi & Presidente da Argentina & 3 & 3 \\
\hline Charles de Gaulle & Presidente da França & 2 & 2 \\
\hline Golda Meir & MRE israelense na & 4 & 1 \\
\hline Arieh Levavi & $\begin{array}{l}\text { Embaixador israelense } \\
\text { Argentina }\end{array}$ & 4 & 1 \\
\hline Diógenes Taboada & MRE argentino & 1 \\
\hline Mario Amadeo & Embaixador argentino na ONU & 2 & 2 \\
\hline Rodolfo Arias García & Embaixador argentino em Israel & 1 & 0 \\
\hline Pinhas Rosen & Ministro da Justiça argentino & 1 & 0 \\
\hline Silvano Santander & $\begin{array}{l}\text { Diretor da Unión Civica Radical } \\
\text { (partido argentino) }\end{array}$ & 1 & 0 \\
\hline Agustin Rodriguez Araya & Deputado argentino & 0 & 1 \\
\hline Abraham Selinger & $\begin{array}{l}\text { Comandante da investigação no } \\
\text { caso Eichmann }\end{array}$ & 1 & 1 \\
\hline Konrad Adenauer & Chanceler Alemão & 1 & 0 \\
\hline Nahum Goldmann & $\begin{array}{l}\text { Presidente da Federação Sionista } \\
\text { Mundial }\end{array}$ & 2 & 0 \\
\hline Total de notícias & & 15 & 11 \\
\hline
\end{tabular}

Quadro 4: Personalidades políticas citadas

Fonte: elaboração própria.

Observe que enquanto La Prensa cita diversas vezes tais autoridades políticas, $\mathrm{La}$ Razon o faz numa frequência notavelmente menor. Somente La Prensa preocupou-se em publicar as notas oficiais trocadas entre Israel e Argentina, ao passo que La Razon apenas teceu breves comentários sobre esses documentos. É possível avaliar o grau de inserção do jornal nas questões políticas mundiais através desses aspectos. Conforme dito no tópico anterior, o jornal La Razon tinha como prioridade fornecer notícias breves e de informação geral em lugar de matérias extensas sobre os rumos da política. A forma como o caso Eichmann foi tratado pelo jornal no período analisado manifesta a atenção dada em menor nível a aspectos da política mundial.

Não é novidade a discussão sobre a mídia exercendo o papel da justiça ao antecipar o julgamento de um caso. Volnei Ivo Carlin, em A mídia e a justiça (1998), afirma que o jornalista de investigação contemporâneo quer ser, ao mesmo tempo, 
informante e julgador. É isso que observamos nas notícias veiculadas por La Prensa e La Razon no tocante ao caso Eichmann. Termos como: "el mayor enemigo viviente del pueblo judío" (La Razon, 26/05/1960); “el hombre que asesinó a seis millones de judíos" (La Razon, 05/06/1960); “el exterminador de judios” (La Prensa, 27/05/1960) e "el principal verdugo [carrasco] de la Alemania nazi”" (La Prensa, 28/05/1960), exprimem a tentativa dos jornais de assumir um papel de juiz no caso, condenando o acusado antes que este respondesse perante um tribunal pelas acusações que lhe foram imputadas.

O quadro abaixo é resultado da análise do posicionamento dos jornais frente ao caso Eichmann. Nele podemos verificar a quantidade de notícias que o trataram como “acusado", "condenado" ou não fizeram referências diretas a sua pessoa. Das notícias que empregavam algum juízo sobre o ex-oficial nazista, no que diz respeito ao La Prensa, $50 \%$ referiram-se a ele com termos expressamente condenatórios e outros $50 \%$ dirigiramse a ele com termos como "acusado pela matanza de seis millones de judíos en la Alemania nazi" (La Prensa, 30/05/1960) e "hombre que será procesado por su participación en el exterminio de millones de judíos durante el Tercer Reich" (La Prensa, 03/06/1960). Por sua vez, em La Razon, o percentual é de 90,9\% das notícias de tom explicitamente condenatório.

\begin{tabular}{|l|l|l|}
\hline Referências a Eichmann & La Prensa & La Razon \\
\hline "Acusado" & 7 & 0 \\
\hline "Condenado" & 7 & 10 \\
\hline Sem referências & 1 & 1 \\
\hline Total de noticias & 15 & 11 \\
\hline \multicolumn{2}{|c|}{ Quadro 5: Referências a Eichmann } \\
Fonte: elaboração própria.
\end{tabular}

Nota-se, portanto, uma mídia não mais satisfeita em apenas informar, mas que procura intervir diretamente no curso dos acontecimentos, exercendo um papel que cabe à justiça, como o de julgar e sentenciar um indivíduo, que se torna criminoso apenas quando comprovados os crimes sob os quais foi acusado (CARLIN, 1998, p. 21). Preocupado com a necessidade que cada qual (mídia e justiça) tem de ocupar seu papel no cenário social, Carlin (1998) adverte:

$\mathrm{Na}$ realidade, o espaço público, entendido este como possibilidade de exteriorizar uma ideia, ocorre mediante o equilíbrio entre um poder instituído e impulsionado por procedimentos, a Justiça instalada, e um outro poder, não 
instituído: a imprensa. Necessário, pois, que cada qual permaneça em seu campo de ação, sem incorrer no crasso erro de desempenhar os dois papéis (CARLIN, 1998, p. 21).

\section{Considerações finais}

O jornalismo, no seio da indústria cultural, não se distancia muito de um enredo de novela. Diariamente nos vemos expostos aos mais variados conteúdos, passando da política ao esporte, da cultura à economia, da saúde ao internacional e mais uma gama de assuntos que fazem parte do nosso cotidiano. As histórias se repetem todos os dias e a cada "capítulo", uma "surpresa" visa seduzir o público leitor.

Não foi ao acaso que o as notícias sobre Adolf Eichmann preencheram centenas de páginas de jornais e revistas argentinos e internacionais da época. Mais que a atenção jornalística, o anúncio da prisão do nazista desencadeou uma enxurrada de sentimentos na comunidade argentina, dentre os quais: revolta, indignação, senso de justiça, dor, compaixão e solidariedade.

Os resultados desta análise permitiram identificar equívocos na cobertura do caso Eichmann pelos jornais impressos La Prensa e La Razon tais como: sensacionalismo nas manchetes; exploração excessiva de repetições de temas; exposição problemática da imagem do acusado, ausência de assinatura dos jornalistas nos textos publicados e alguns casos de ausência de fontes. Estes equívocos são comuns ao padrão exigido por uma indústria cultural, que no caso da imprensa, tem como produto final a notícia que vende, sem a mínima preocupação com a origem e o conteúdo da informação divulgada.

O tom escandaloso presente nas manchetes reflete um aspecto da cultura de massas levantado por Morin (1997) - quando elementos romanescos são frequentemente inventados ou imaginados pelos jornalistas para sensibilizar o público e estimular o consumo (MORIN, 1997, p. 36-37). O uso dessa linguagem resulta num paradoxo: os jornais impulsionam as vendas, porém são considerados antiéticos, na medida em que tem sua credibilidade discutível.

Em alguns casos, não houve sequer o cuidado em averiguar se uma simples informação recebida estava correta, como na notícia de $1^{\circ}$ de junho, em que um jornalista do La Razon entrevista a esposa de Klaus em sua residência. A matéria não informa o nome da mulher entrevistada (deixando de responder a uma das principais perguntas do 
lead: “quem?") e menciona que o casal tem um filho (hijo) pequeno ${ }^{17}$. Três dias depois, a notícia de 4 de junho informa que o casal e a filha (hija) pequena deixaram a casa no bairro de Olivos acompanhados según hemos podido saber de três homens num carro com placa da capital federal ${ }^{18}$. Eis aí um claro exemplo de cobertura cuja credibilidade foi comprometida.

No tocante à exposição problemática da imagem do acusado, compreende-se que apesar dos esforços de ambos os periódicos em "diabolizar" a figura do nazista, Adolf Eichmann de fato não era um criminoso comum - que marcha contra o status quo legal e moral da sociedade em que vive - mas tampouco era um “monstro". Segundo Hannah Arendt, em Eichmann em Jerusalém (2013), bastava que o acusado relembrasse seu passado para se sentir seguro de que ele e o mundo em que viveu marcharam um dia em perfeita harmonia, assim também como a sociedade alemã de 80 milhões de pessoas que se protegeu contra a realidade e os fatos com a mesma prerrogativa - de que apenas seguia ordens superiores (ARENDT, 2013, p. 64-65). Em sua obra, a filósofa resume no conceito de "banalidade do mal" o resultado da massificação (padronização) da sociedade, processo no qual se cria uma multidão incapaz de fazer julgamentos morais, razão porque aceitam e cumprem ordens sem questionar.

Nesse sentido, para que as contundentes assertivas de La Prensa e La Razon sobre Eichmann correspondessem à realidade dos fatos, era preciso (I) que o nazista ocupasse um cargo de destaque na hierarquia do Terceiro Reich, para que se encarregasse de arquitetar planos de extermínio de judeus; e (II) que se condenasse com ele toda uma sociedade de "monstros".

A primeira hipótese já foi descartada no início deste trabalho (vide "Anexo I"). Quanto à segunda, compartilha-se aqui da visão de que o nazismo não foi um feito de monstros. Conforme Garapon, em O juiz e a democracia (2001): “[O nazismo] era todo um sistema, toda uma burocracia, uma estrutura estatal composta de gente 'comum' que trabalhava pacientemente para a realização da Proposta Final, apoiando-se no aparelho de um grande Estado moderno" (GARAPON, 2001, p. 90-91). Outrossim, ao exercerem o papel de juízes do caso, os jornais depositaram sobre Eichmann todos os crimes

\footnotetext{
${ }^{17}$ Disponível no Jornal La Razon, “Cómo fue identificado y apresado Eichmann”, 01 jun. 1960.

${ }^{18}$ Disponível no Jornal La Razon, "Otro misterio en el caso Eichmann: desaparecen la mujer y los hijos", 04 jun. 1960.
} 
cometidos durante o regime nazista, atribuindo-lhe algumas responsabilidades sobre as quais sua função não lhe permitia a menor ingerência ${ }^{19}$.

Outro aspecto percebido nesta análise foi que, guardadas as proporções, ambos os periódicos terminam por produzir um discurso semelhante sobre Eichmann, suas atividades no sistema nazista e seu sequestro por agentes israelenses. Isso se deve ao fato de que na construção da seção internacional do jornal, as empresas que não dispõem de correspondentes no estrangeiro dependem do material disponibilizado pelas agências de notícias, o que incorre em características como a homogeneidade do noticiário internacional e a cristalização de discursos (BOMFIM; MÜLLER, 2016, p. 65). Tal fato, todavia, não exime da redação do jornal a tarefa de investigação do conteúdo recebido antes de sua publicação.

Concluímos o presente artigo constatando que ambos os jornais, a despeito de suas divergências editoriais - em suas tentativas de antecipar a justiça sobre o caso Eichmann, verificadas nos termos utilizados para referir-se ao nazista - elevaram-no de um funcionário pouco conhecido, sem papel proeminente na hierarquia do Terceiro Reich, ao patamar de "el principal responsable del extermínio de los judíos de Europa" (La Prensa, 27 mai. 1960) e "individuo que proyectó la liquidación de la raza hebraica" (La Prensa, 07 jun. 1960), termos estes dotados de um sensacionalismo aberto. Como consequência, nota-se um proceso de mitificação da figura de Eichmann pelos jornais argentinos, uma completa transformação deste num personagem, num inimigo cruel, num notável carrasco.

${ }^{19}$ Como exemplo, o planejamento da Solução Final. Tal plano foi estruturado no contexto da alta cúpula de liderança nazista, da qual Eichmann não integrava. 


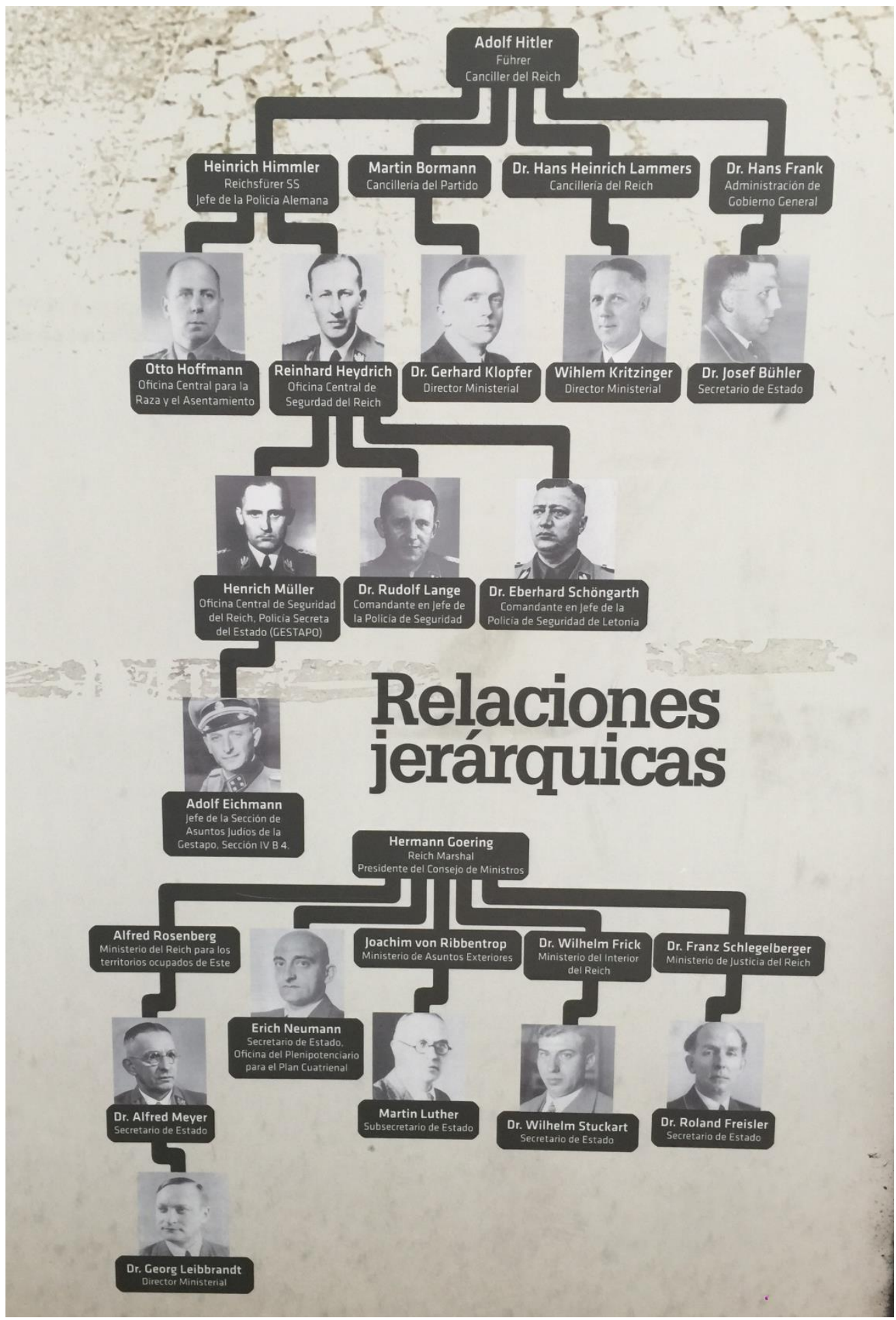

Organograma 1: Hierarquia Nazista.

Fonte: Museu do Holocausto de Buenos Aires

\section{Referências bibliográficas}

ADORNO, T. W.; HORKHEIMER, Max. Dialética do esclarecimento: fragmentos filosóficos. $2^{\mathrm{a}}$ ed. Rio de Janeiro: Jorge Zahar, 1986. 
ARENDT, H. Eichmann em Jerusalém: um relato sobre a banalidade do mal. Tradução de José Rubens Siqueira. São Paulo: Companhia das Letras, 2013.

BARDIN, L. Análise de Conteúdo. Edições 70, 2011.

BOMFIM, I. E.; MÜLLER, Karla. M. Diplomacia Midiática e Jornalismo Internacional: As Notícias Globais no Âmbito da Política Externa. Teresina: FSA, n. 5, v. 13, p. 61-79, 2016.

CAMPOS, M. T. C. de. Mitos da mídia. Belo Horizonte: E-com, n. 2, v. 2, 2008, p. 1-14.

CARLIN, V. I. A mídia e a justiça. Florianópolis: Sequência, n. 36, v. 19, 1998, p. 2024.

CORREIA, K. M. V. Análise de Conteúdo do Jornalismo Impresso Natalense. Natal. 2007. 167p. Monografia (Bacharelado em Comunicação Social) - Departamento de Comunicação Social da Universidade Federal do Rio Grande do Norte.

GARAPON, A. O juiz e a democracia, o guardião das promessas. $2^{\mathrm{a}}$ ed. Rio de Janeiro: Revan, 2001.

MORIN, E. Cultura de Massas no Século XX: Neurose. Tradução de Maura Ribeiro Sardinha. Rio de Janeiro: Forense Universitária, 1997.

SENKMAN, L. "La question de los refugiados judíos en Argentina y Brasil: la perspectiva de la política internacional y del neutralismo, 1938-1942”. In: MILGRAM, Avraham (Org.). Entre la aceptación y el rechazo: América Latina y los refugiados judíos del nazismo. Jerusalém: Yad Vashem, 2003.

SOARES, D. A. M. Adolf Eichmann, o Estado argentino e a questão dos criminosos nazistas na Argentina (1945-1962). Rio de Janeiro. 2017. 67p. Monografia (Bacharelado em Relações Internacionais) - Departamento de História e Relações Internacionais da Universidade Federal Rural do Rio de Janeiro.

SOARES, D.; XAVIER, A.; WEY, B. O julgamento espetáculo de Adolf Eichmann. Toledo: Tempo da Ciência, n. 47, v. 24, 2017, p. 76-90.

SOUSA, J. P. Introdução à análise do discurso jornalístico impresso. Letras Contemporâneas, 2004.

WOLF, M. Teorias da Comunicação. Tradução de Maria Jorge Vilar de Figueiredo. Lisboa: Editorial Presença, 1999.

ZOCOLER, M. R. O Tribunal Militar Internacional para a Alemanha: Tribunal de Nuremberg: seu caráter de exceção e o princípio da legalidade. Teresina: Revista Jus Navigandi, n. 3766, 2013. 